TÀI LIỆU THAM KHẢO

1. Bộ Y tế (2015), "Tiêu chảy cấp", Hướng dẫn chẩn đoán và điều trị một số bệnh thường gặp ở trẻ em, Hà Nội, Nhà xuất bản y học, tr. 316-324.

2. Lương Cao Đồng (2015), "Đánh giá hiệu quả điêuu trị tiêu chảy cấp do Rotavirus bằng Racecadotril ở bệnh nhi dưới 6 tuổi điều trị tại khoa Nhi, Bênh viện quân y 103 ", Tạp chí Y'Dược học quần sự. 5, tr. 105-111.

3. Lê Tấn Giàu, Trương Công Đây và Ta Văn Trâm (2017), "Đặc điểm bệnh tiêu chảy cẩp điều trị nội trú tại khoa Nhi Bệnh viện đa khoa trung tầm Tiên Giang từ 01/8/1016 đến 31/10/2016 ", Tạp chí y học thành phố Hồ Chí Minh. 21(6), tr. 1-4.

4. Vũ̃ Thị Huyền (2010), Đánh giá kết quả điều trị hỗ trợ bệnh tiêu chảy cấp bằng thuốc kháng tiết đường ruột hidrasec tại khoa nhi - bệnh viện đa khoa Trung ương Thái Nguyên, Luận vằn thạc sỹ y học, Trường đại học Y Dược Thái Nguyên.
5. Đỗ Phương Thảo (2015), Đặc điểm dịch tễ học lâm sàng bệnh tiêu chảy cấp do rotavirus ở trẻ dưới 5 tuổi tai bệnh viện Nhi Trung Ương, Luận văn bác sỹ nội trú, Trường đại học Y Hà Nội.

6. Phạ Võ Phướng Thảo (2021), "Nghiên cứu đă̆c điểm lâm sàng và cận lâm sàng bệnh tiêu chảy cấp ở trẻ từ 2 tháng đến 5 tuối tại Bệnh viện Trung ương Huế", Tap chí Y Dược học - Trường Đại học Y Dược Huế. Số 1(11), tr. 24-29.

7. Nguyê̂n Thành Trung (2015), Nghiên cứu đăc điểm lâm sàng, cận lâm sàng và một số tác nhẩn gây bênh tiêu chảy cấp ở trẻ em, Luẩn văn Thac sỹ của Bác sĩ nội trú, Trường Đại học Y Dược Huế.

8. Nshimiyimana, Ladislas Onyambu, Peris Monchari Rutayisire et al (2020), "Diarrhoeal Diseases in Children Under Five Years Exhibited Space-Time Disparities and Priority Areas for Control Interventions in Rwanda 08 May 2020", PREPRINT (Version 1) available at Research Square.

\title{
ĐẶC ĐIỂM HÌNH ẢNH THỦNG TẠG RỖNG TRÊN X QUANG, CẮT LỚP VI TÍNH VÀ SIÊU ÂM Ổ BỰG
}

\author{
Nguyễn Văn Thắng*, Nguyễn Thành Luân*, Đinh Việt Khôi*
}

\section{TÓM TẮT}

Mục tiêu: Mô tả một số đặc điểm hình ảnh bênh lý thủng tạng rỗng trên x quang, cắt lớp vi tính và siêu âm ổ bụng. Đối tượng và phương pháp: Nghiên cứu mô tả cắt ngang 31 bệnh nhân đến khám cấp cứu bụng và được chẩn đoán xác định là thủng tạng rỗng tại bênh viên Hữu Nghi Việt Đức từ 11/2020 đến 05/2021. Kết quả: Tống cộng $31 \mathrm{BN}$, bao gồm 23 nam $(74.2 \%)$ và 8 nữ $(25.8 \%)$. Tuổi mắc bênh trung bình $53,77 \pm 21,9$. Thủng tá tràng chiếm tỷ lệ cao nhất $(32.25 \%)$, tiếp đến là da dày và ruôt non $(25.8 \%)$. Trên x quang bụng cấp cứu, dẫu hiệu dịch tự do ổ bung chiếm $73.3 \%$, dấu hiếu liềm hơi dưới hoành chiếm $23.3 \%$. Trên cắt lớp vi tính ổ bụng, dấu hiệu khí ngoài ống tiêu hóa chiếm $74.2 \%$, thâm nhiễm mỡ mạc treo chiếm $71 \%$. Trên siêu âm ổ bụng, dấu hiệu "rèm cửa" chỉ thây được ở 3 trường hợp (chiếm 13\%).

Tư khóa: Thủng tạng rông, $X$ quang, Cắt lớp vi tính, Siêu âm ổ bụng

\section{SUMMARY \\ IMAGING CHARACTERISTICS ON KUB X- RAY, CT AND ABDOMINAL SONOGRAPH IN PNEUMOPERITONEUM}

Purpose: To describe imaging characteristics on KUB x-ray, abdominal CT and abdominal sonograph in pneumoperitoneum. Material and method: Descriptive cross-sectional study on 31 patients who

*Trường Đại học Kỹ thuật Y tế Hải Dương

Chịu trách nhiệm chính: Nguyễn Văn Thắng

Email: nguyenvanthang@hmtu.edu.vn

Ngày nhận bài: 7.6.2021

Ngày phản biên khoa hoc: 4.8.2021

Ngày duyệt bài: 13.8.2021 admitted to Viet Duc hospital for acute pain in their abdomen and diagnosed pneumoperitoneum from November 2020 to May 2021. Result: A total of 31 patients included 23(74.2\%) males and $8(25.8 \%)$ females: mean age is $53,77 \pm 21,9$. Doudenal perforation was showed hightest $(32.3 \%)$, stomach and intestinal perforation (25.8\%). On KUB x-ray, free peritoneal effusion was showed $73.3 \%$, subdiaphragmatic free gas was showed $23.3 \%$. On abdominal computer tomography, extragastrointestinal gas was showed $73.3 \%$. On abdominal sonograph, peritoneal stripe sign was showed

Keywords: Pneumoperitoneum, KUB x-ray, abdominal sonographer

\section{I. ĐẶT VẤN ĐỀ}

Thủng tạng rỗng là một trong những cấp cứu bụng ngoại khoa thường gặp nhất, nguyên nhân có thể là một trong những biến chứng của ổ loét dạ dày-tá tràng, viêm ruột cấp hay các biến chứng của phẫu thuật, nội soi. Các phương pháp chẩn đoán hình ảnh như siêu âm, chụp $x$ quang và cắt lớp vi tính ổ bụng cho những hình ảnh có giá trị đặc hiệu và tin cậy giúp chẩn đoán và xử trí kịp thời. Chẩn đoán bằng $x$ quang đem lại hiệu quả rất cao với việc phát hiện rõ liềm hơi dưới cơ hoành [1]. Tuy nhiên, khi lượng khí rất bé, chỉ vài $\mathrm{mm}$ thì trên màn ảnh $x$ quang sẽ khó phát hiện được. Những năm gần đây, vaii trò của siêu âm trong chẩn đoán thủng tạng rỗng được nhiều nhà chẩn đoán hình ảnh báo cáo là phương pháp thăm khám có giá trị tuy nhiên phụ thuộc nhiều vào người làm siêu âm. Dấu hiệu 
đặc trưng để chẩn đoán thủng tạng rỗng là thấy hình ảnh "rèm cửa" và dịch tự do trong ổ phúc mạc, khoang sau phúc mạc. Chụp cắt lớp vi tính cho phép xác định khí tự do trong ổ bụng dù lượng khí có thể rất ít, chỉ một vài bóng khí. Hơn thế nữa, cắt lớp vi tính có thể cho thấy nguyên nhân trong phần lớn các trường hợp, điêu mà cả $x$ quang lần siêu âm khó cho thấy được. Nhằm góp phần củng cố thêm vai trò của các phương pháp thăm khám hình ảnh phổ biến này trong bệnh lý thủng tạng rỗng, chúng tôi tiến hành nghiên cứu này với mục tiêu: "Mô tả môt số đặc điểm hinh ảnh bênh lý thủng tạng rỗng trên $x$ quang, cắt lớp vi tính và siêu âm ố bụng".

\section{II. ĐỐI TƯợNG VÀ PHƯƠNG PHÁP NGHIÊN CỨU}

- Tất cả các bênh nhân được chẩn đoán và điều trị bệnh lý thủng tạng rỗng tại bệnh viện Hữu Nghị Việt Đức từ tháng 11 năm 2020 đến tháng 5 năm 2021.

- Loại trừ những bệnh nhân mới có can thiệp phẫu thuật hoặc thăm dò ổ bụng trong vòng 1 tháng hoặc khônng đồng ý tham gia nghiên cứu.

- Dấu hiệu thủng tạng rỗng trên $x$ quang: Liềm hơi dưới vòm hoành 1 hoặc 2 bên, dày thành quai ruột, dịch giữa các quai ruột và rãnh thành đại tràng, mờ vùng thấp ổ bụng

- Dấu hiệu thủng tạng rỗng trên siêu âm: Khí tự do trong ổ bụng, dịch tự do trong ổ bụng, dày thành quai ruột.

- Dấu hiệu thủng tạng rỗng trên cắt lớp vi tính: Khí tự do trong ổ bụng hoặc sau phúc mạc, dịch tự do ổ bụng, thâm nhiếm mõ mạc treo, dày thành quai ruột và ngấm thuốc mạnh, thoát thuốc cản quang qua đường uống ra ngoài lòng ruột.

- Số liệu thu thập sẽ xử lý và phân tích trên phần mềm thống kề SPSS 20.0. Tất cả các biến sẽ được trình bày dưới dạng các bảng.

\section{KẾT QUẢ NGHIÊN CỨU}

3.1. Một số đặc điểm chung của đối tượng nghiên cứu.

Bảng 3.1. Mốt số đặc điểm chung của đôi tượng nghiên cứu

\begin{tabular}{|c|c|c|}
\hline \multicolumn{2}{|c|}{ Đặc điểm chung } & $\begin{array}{c}\text { Tân suất } \\
(\%)\end{array}$ \\
\hline \multirow{3}{*}{ Giới } & Nam & $23(74.2)$ \\
\cline { 2 - 3 } & Nữ & $8(25.8)$ \\
\hline \multirow{4}{*}{ Nhóm } & $<16$ & $2(6.5)$ \\
\cline { 2 - 3 } tuổi & $16-25$ & $2(6.5)$ \\
\cline { 2 - 3 } & $26-35$ & $2(6.5)$ \\
\cline { 2 - 3 } & $36-45$ & $4(12.9)$ \\
\cline { 2 - 3 } & $45-55$ & $7(22.6)$ \\
\cline { 2 - 3 } & $56-65$ & $5(16.1)$ \\
\cline { 2 - 3 } & $>65$ & $9(28.9)$ \\
\hline
\end{tabular}

\begin{tabular}{|c|c|c|}
\hline \multirow{5}{*}{$\begin{array}{l}\text { Vị trí } \\
\text { tổn } \\
\text { thương }\end{array}$} & Dạ dày & $8(25.8)$ \\
\hline & Tá tràng & $10(32.3)$ \\
\hline & Ruột non & $8(25.8)$ \\
\hline & Đại tràng & $7(19.4)$ \\
\hline & Ruột thư̌a & $2(6.5)$ \\
\hline \multirow{5}{*}{$\begin{array}{l}\text { Nguyên } \\
\text { nhân }\end{array}$} & Chấn thương & $8(25.8)$ \\
\hline & $\begin{array}{c}\text { Thủng ố loét dạ dày, tá } \\
\text { tràng }\end{array}$ & $11(35.5)$ \\
\hline & $\begin{array}{l}\text { Viêm ruột thừa, túi } \\
\text { thừa đại tràng }\end{array}$ & $4(12.9)$ \\
\hline & Viêm ruột cấp tính & $2(6.5)$ \\
\hline & Các khối u ác tính & $\begin{array}{c}1(3.2) \\
5(361)\end{array}$ \\
\hline
\end{tabular}

Nhận xét: Bệnh nhân là nam chiếm tỷ lệ $(74.2 \%)$, cao hơn so với nữ $(25.8 \%)$, sự khác biệt có ý nghĩa thống kê $(p<0,05)$. Tỷ lệ nam/nữ là 2.9, tuổi trung bình là $53,77 \pm 21,90$. Trong 31 bệnh nhân với 35 lỗ thủng tại 5 vị trí được xác định, thủng tá tràng hay gặp nhất, chiếm 32.3\%, thủng tại ruột thừa ít gặp nhất, chiếm $6.5 \%$. Nguyên nhân hay gặp nhất của thủng tạng rỗng là do thủng ổ loét dạ dày-tá tràng (chiếm $35.5 \%$ ), chỉ có 01 trường hợp do $u$ ác tính ống tiêu hóa, có tới 5 trường hợp (16.1\%) không tìm thấy nguyên nhân.

\section{2. Đặc điểm hình ảnh bệnh lý thủng} tạng rỗng

Bảng 3.2. Đặc điểm hình ảnh bệnh lý thủng tạng rống trên $x$ quang

\begin{tabular}{|c|c|c|}
\hline \multicolumn{2}{|c|}{$\begin{array}{c}\text { Đắc điểm thủng tạng rống } \\
\text { trển } \mathbf{x} \text { quang buụng cấp cứu }\end{array}$} & $\begin{array}{c}\text { Tân suất } \\
(\%)\end{array}$ \\
\hline \multirow{3}{*}{$\begin{array}{c}\text { Dấu hiệu } \\
\text { thưng } \\
\text { tạng rô̂ng }\end{array}$} & Liềm hơi dưới hoành & $7(23.3)$ \\
\cline { 2 - 3 } & Dày thành quai ruột & $19(63.3)$ \\
\cline { 2 - 3 } & $\begin{array}{c}\text { Dịch giữa quai ruột, } \\
\text { rãnh thành đại tràng }\end{array}$ & $22(73.3)$ \\
\cline { 2 - 3 } & Mờ vùng thấp ố bụng & $22(73.3)$ \\
\hline \multirow{2}{*}{$\begin{array}{c}\text { Vị trí liềm } \\
\text { hơi }\end{array}$} & Bên trái & $1(14.3)$ \\
\cline { 2 - 3 } & Bên phải & $4(57.1)$ \\
\cline { 2 - 3 } & Hai bên & $2(28.6)$ \\
\hline
\end{tabular}

Nhận xét: Hình ảnh phản ánh có dịch tự do ổ bụng hay gặp nhất, chiếm $73.3 \%$. Dấu hiệu liềm hơi dưới hoành chỉ thấy ở 7 trường hợp (23.33\%). Hình liềm hơi dưới hoành được quan sát nhiều hơn ở bên phải.

Bảng 3.3. Đặc điểm hình ảnh bệnh lý thủng tạng rống trên cắt lớp vi tính

\begin{tabular}{|c|c|c|}
\hline $\begin{array}{c}\text { Đặc điếm thủng tanng rông trên } \\
\text { cắt lớp vi tính ổ bụng }\end{array}$ & $\begin{array}{c}\text { Tân suất } \\
\text { (\%) }\end{array}$ \\
\hline \multirow{2}{*}{$\begin{array}{c}\text { Dấu hiệu } \\
\text { thủng tạng } \\
\text { rồng }\end{array}$} & $\begin{array}{c}\text { Khí trong ố bụng hoặc } \\
\text { sau phúc mạc }\end{array}$ & $23(74.2)$ \\
\cline { 2 - 3 } $\begin{array}{c}\text { Dịch tự do trong ố } \\
\text { bụng }\end{array}$ & $31(100)$ \\
\cline { 2 - 3 } & $\begin{array}{c}\text { Khí + dịch tự do trong } \\
\text { ổ bụng }\end{array}$ & $19(61.3)$ \\
\hline
\end{tabular}




\begin{tabular}{|c|c|c|}
\hline & $\begin{array}{l}\text { Thành ruột dày và } \\
\text { ngấm thuốc mạnh }\end{array}$ & $25(75.8)$ \\
\hline & Thâm nhiềm mỡ mạc treo & $22(71)$ \\
\hline & $\begin{array}{l}\text { Thoát thuốc cản quang } \\
\text { ra ngoài lòng ruột }\end{array}$ & $1(100)$ \\
\hline \multirow{9}{*}{$\begin{array}{l}\text { Khí ngoài } \\
\text { lòng ruột }\end{array}$} & Mặt trước gan & 9(29) \\
\hline & Vùng thượng vị & $3(9.7)$ \\
\hline & Canh tá tràng & $3(9.7)$ \\
\hline & Cạnh đại tràng & $2(6.5)$ \\
\hline & Canh da dày & $2(6.5)$ \\
\hline & Dưới thành bụng trước & $4(13)$ \\
\hline & $\begin{array}{c}\text { Phía trên mạc treo đại } \\
\text { tràng ngang }\end{array}$ & $2(6.5)$ \\
\hline & Các vị trí khác & $6(19.3)$ \\
\hline & Không thấy khí tự do & $8(25.8)$ \\
\hline \multicolumn{2}{|c|}{$\begin{array}{c}\text { Độ dày trung bình thành ruột } \\
(\mathrm{n}=25)\end{array}$} & $\begin{array}{c}\text { Tần suất } \\
(\%)\end{array}$ \\
\hline $\begin{array}{l}\text { Quai ruột } \\
\text { non }\end{array}$ & 16,4 & $5(20)$ \\
\hline $\begin{array}{l}\text { Môn vị dạ } \\
\text { dày }\end{array}$ & 22 & $1(4)$ \\
\hline Đại tràng & 15 & $3(12)$ \\
\hline $\begin{array}{l}\text { Tá tràng, } \\
\text { hành tá tràng }\end{array}$ & 7 & $2(8)$ \\
\hline Ruột thưa & 12 & $1(4)$ \\
\hline
\end{tabular}

Nhân xét: Tất cả các trường hợp thủng tạng rỗng đểu thây dịch tự do trong ổ bụng. Hình khí ngoài ống tiêu hoá được thấy ở 23 trường hợp (chiếm 74.2\%). Trong đó, khí tự do mặt trước gan gặp ở 9 trường hợp (29\%), dưới thành bụng trước 4 trường hợp (13\%). Có 1 trường hợp có dùng thuốc cản quang đường uống và thấy thoát thuốc cản quang ra ngoài lòng ruột. Có 25 trường hợp có dấu hiệu dày thành ruột, trong đó ở ruột non xuất hiện nhiều nhất $(20 \%)$. Môn vị dạ dày là vị trí có độ dày trung bình dày nhất $(22 \mathrm{~mm})$ và vị trí mất liên tục thành ruột rộng nhất (5mm).

Bảng 3.4. Đặc điểm hình ảnh bênh lý thủng tạng rống trên siêu âm

\begin{tabular}{|c|c|c|}
\hline \multicolumn{2}{|c|}{$\begin{array}{c}\text { Đặc điếm thủng tạng rông trên } \\
\text { siêu âm }\end{array}$} & $\begin{array}{c}\text { Tân suất } \\
(\%)\end{array}$ \\
\hline \multirow{4}{*}{$\begin{array}{l}\text { Dấu hiệu } \\
\text { thưng tạng } \\
\text { rống }\end{array}$} & Hình "rèm cửa" & $3(13)$ \\
\hline & $\begin{array}{l}\text { Dịch tự do trong ố } \\
\text { bụng }\end{array}$ & $18(78.3)$ \\
\hline & $\begin{array}{l}\text { Khí + dịch tự do } \\
\text { trong ổ bụng }\end{array}$ & $1(4.4)$ \\
\hline & $\begin{array}{l}\text { Dày thành ruột + } \\
\text { dịch xung quanh }\end{array}$ & $9(39.1)$ \\
\hline $\begin{array}{l}\text { Vị trí dấu hiệu } \\
\text { "rèm cửa" }\end{array}$ & Mặt trước gan phải & $3(100)$ \\
\hline
\end{tabular}

Nhânn xét: Trong số 23 bệnh nhân được thực hiện siêu âm, chỉ có 3 trường hợp (chiếm $13 \%$ ) được phát hiện có tràn khí tự do ổ bụng với dấu hiệu đặc trưng là hình ảnh "rèm cửa", cả 3 trường hợp này khí đều được quan sát thấy ở mặt trước gan phải.

\section{BÀN LUÂN}

4.1. Đặc điểm chung của đối tượng nghiên cứu. Nghiên cứu 31 bệnh nhân được chẩn đoán thủng tạng rỗng tại Bệnh viện Việt Đức từ tháng 10 năm 2020 đến tháng 4 năm 2021, chúng tôi thấy có 23 bệnh nhân nam, chiếm $(74.2 \%)$, cao hơn nữ $(25.8 \%)$, sự khác biệt có ý nghĩa thống kê $(p<0.05)$. Độ tuối trung bình của bệnh nhân thủng tạng rỗng là $53,77 \pm 21,90$. Trong số 31 bệnh nhân với 35 lỗ thủng được xác nhận tại 5 vị trí, thủng tá tràng chiếm tỷ lệ cao nhất, chiếm 32.25\%. Nghiên cứu của Nguyến Thị Mai Sương và CS cũng cho thấy tỷ lệ thủng dạ dày- tá tràng không do chấn thướng chiếm tỷ lệ cao nhất $(78,4 \%)[2]$. Thủng tạng rỗng do chấn thương chúng tôi gặp ở 8 trường hợp (chiếm 25.8\%). Về nguyên nhân do chấn thương, nghiên cứu của chúng tôi cho kết quả cao hơn so với trong báo cáo của Nguyễn Thị Mai Sương và CS, tỷ lệ này là $16.4 \%[2]$. Tuy nhiên, Nguyễn Văn Tiệp và CS (2018) cho thây nguyên nhân chiếm tới 70.5\%[3].

4.2. Đặc điểm hình ảnh bệnh lý thủng tạng rỗng. Trong nghiên cứu này, có 30 bệnh nhân được chụp $x$ quang bụng cấp cứu. Trên $x$ quang, dấu hiệu cho thấy có dịch tự do ổ bụng chiếm $73.3 \%$. Dấu hiệu dày quai ruột do phù nề gặp ở 19 trường hợp (63.3\%). Dấu hiệu đặc trưng có ý nghĩa chẩn đoán xác định là hình liềm hơi dưới vòm hoành chỉ thấy ở 7 trường hợp (chiếm 23.3\%), như vậy việc không quan sát thấy hình liềm hơi trên $x$ quang chúng ta vẫn cần cảnh giác cao độ khi chúng ta chưa giải thích được các biểu hiện của bệnh trên lâm sàng. Tỷ lệ phát hiện thấy hình liềm hơi trong nghiên cứu này thấp hơn so với tỷ lệ được cáo cáo trong nhiều nghiên cứu đã công bố trước đây được giải thích do cơ sở để tiến hành nghiên cứu là bệnh viện hàng đầu về cấp cứu bụng ngoại khoa, hơn nửa lại nằm ở trung tâm của thành phố nên việc người bệnh được nhập viện sớm sau khi khởi phát cơn đau, khi lượng khí tràn vào ổ bụng quá ít nên trên $x$ quang đã không thấy được. Mặt khác, một số bệnh nhân có biểu hiện lâm sàng nặng, khó khăn khi đứng hay tư thế nửa nằm nửa ngồi, nằm nghiêng trong khi chụp cũng làm cho việc phát hiện liềm hơi khó khăn. Tỷ lệ dấu hiệu này gặp trong nghiên cứu cửa Nguyễn Thị Mai Sương và CS (2014) và Nguyễn Văn Tiệp và CS (2018) lần lượt là $86.9 \%$ và $36.4 \%[2,3]$. Về vị trí liềm hơi, dưới hoành phải gặp nhiêuu hơn so 
với dưới hoành trái, đô dày trung bình của liềm hơi là $3.5 \mathrm{~mm}$. Nguyễn Thị Mai Sương và CS (2014) cũng cho thấy liềm hơi gặp nhiều hơn ở bên phải (chiếm 42.5\%)[2]. Trong nghiên cứu này, chỉ có 3 trường hợp trong tổng số 23 bệnh nhân được thực hiện siêu âm ổ bụng được phát hiện có khí tự do trong ổ bụng. Về dấu hiệu này, tỷ lệ phát hiện có khí tự do nhờ siêu âm chẩn đoán thấp hởn nhiều so với các nghiên cứu của các tác giả đã công bố trước đó[4]. Tại Việt Nam, việc tìm kiếm dấu hiệu tràn khí tự do ổ bụng trong các trường hợp bệnh nhân bị nghi ngờ có thủng tạng rỗng chưa thực sự được các bác sỹ siêu âm quan tâm nhiều, chính vì vậy việc phát hiện dấu hiệu này còn hạn chế trong thực hành lâm sàng. Nhiều nghiên cứu trước đây đã cho thấy, siêu âm ổ bụng có thể chẩn đoán chính xác tràn khí màng bụng nhưng cũng không nên xác định siêu âm là phương pháp thăm khám duy nhất để chẩn đoán xác định hay loại trừ tràn khí màng bụng[4,5].

\section{KẾT LUÂ̂N}

Qua nghiên cứu 31 trường hợp thủng tạng rỗng tại Bệnh viện Hữu nghị Việt Đức, chúng tôi ghi nhận được một số kết luận như sau:

Thủng tạng rỗng gặp chủ yếu ở nam giới, nguyên nhân hay gặp nhất là do thủng ổ loét dạ dày-tá tràng. Trên $x$ quang, hình liềm hơi dưới hoành chỉ số ít các trường hợp và đa phần thấy ở dưới vòm hoành phải. Tuy nhiên, trên cắt lớp vi tính ổ bụng, có thể quan sát thây hơi ngoài lòng ống tiểu hoá ở phần lớn các trường hợp và có thể thấy thuốc cản quang thoát ra khỏi ống tiêu hoá nếu sử dụng phối hợp thuốc cản quang đường uống. Trên siêu âm, dấu hiệu đặc hiệu là hình ảnh "rèm cửa" ở mặt trước gan, tuy nhiên dẫu hiệu này cũng ít quan sát thấy.

\section{TÀl LIẸU THAM KHẢO}

1. Hoàng, N., N.N. Thắng, and Đ.V. Thời; Đánh giá kết quá phẫu thuật nội soi khâuu lỗ thung dạ dày - tá tràng tại bệnh viện Đà Nắng. Tạp chí khoà học, 2010. 63: p. 63-69.

2. Sương, N.T.M. and L.Đ. Phong;, Đăc điểm lâm sàng và hình ảnh Xquang thường qui ở bệnh nhân thủng tạng rỗng điêu trị tại bệnh viện Đa khoa Trung ương Cần Thớ Tạp chí y học thực hành, 2013. 9(879): p. 65-68.

3. Tiệp, N.V. and Đ.V.D. ; , Chẩn đoán và điều trị tổn thương tạng rống trong chấn thương bụng kín tại bệnh viện Quân y 103. Tạp chí y dược học quân sư 2018. 9: p. 161-167.

4. Jiang, L., J. $\mathbf{W u}$, and $X$. Feng, The value of ultrasound in diagnosis of pneumoperitoneum in emergent or critical conditions: A meta-analysis. Hong Kong Journal of Emergency Medicine, 2018. 26(2): p. 111-117.

5. Grechenig, W., et al., Detection of pneumoperitoneum by ultrasound examination: an experimental and clinical study. Injury, 1999. 30(3): p. 173-8.

\section{MộT SỐ YẾU Tố SẢN KHOA LIÊN QUAN TỬ VONG SƠ SINH SỚM Ở TRẺ ĐẺ NON 28 - 32 TUẦ}

\section{TÓM TẮT}

Mục tiêu: Nhận xét một số yếu tố sản khoa liên quan tử vong sơ sinh sớm ở trẻ đẻ non 28 - 32 tuần. Đối tượng và phương pháp nghiên cứu: Nghiên cứu mô tả cắt ngang trến những trẻ đẻ ra sống ở các trường hợp đơn thai có tuổi thai từ $28^{0 / 7}$ tuần đến hết 320/7 tuần tại Bệnh viện Phụ sản Trung ương trong khoảng thời gian từ 01/07/2020 đến 31/12/2020. Kểt quả: Trong số 238 trường hợp sinh non có 11 trẻ tử vong trong tuần đâu (chiếm tỷ lệ 4,62\%), phân lớn tử vong trong 24 giờ đầu tiên ( $5 / 11$ ca, chiếm 45,45\%). Những nguyên nhân hàng đâuu dẫn tới tử vong ở trẻ là

\section{${ }^{1}$ Đại học Y Hà Nội}

Chịu trách nhiệm chính: Dương Quỳnh Anh

Email: quynhanha4@gmail.com

Ngày nhận bài: 2.6.2021

Ngày phản biện khoa học: 31.7.2021

Ngày duyệt bài: 9.8.2021

\section{Dương Quỳnh Anh' ${ }^{1}$, Phạm Thị Thanh Hiền' ${ }^{1}$}

suy hô hấp (55\%), nhiễm khuẩn $(18 \%)$, xuất huyết não - màng não (18\%). 81,82\% (9/11 ca) trẻ tử vong có me mắc ít nhất một bệnh lý nội khoa hoặc sản khoa, làm tăng khả năng tử vong gấp gần 8 lần ( $O R=$ 7,96, KTC 95\% 1,68 - 37,71), cụ thể rối loạn huyết áp làm tăng gấp 6,3 lần $(\mathrm{OR}=6,37, \mathrm{KTC} 95 \% 1,84-$ $21,98)$. Đồng thời hậu quả thai chậm phát triển trong tữ cung cũng là yếu tố sản khoa làm tăng khả năng tử vong gấp 8,8 lần ( $\mathrm{OR}=8,89$, KTC $95 \% 2,54-31,12$ ). Kết luận: Me bệnh lý (đặc biệt rối loạn huyết áp) và thai chậm phát triển trong tử cung là các yếu tố làm tăng nguy cơ tử vong sơ sinh sớm của trẻ.

Tư khóa: đẻ non, tử vong sơ sinh, yếu tố nguy cơ

\section{SUMMARY}

OBSTETRIC RISK FACTORS FOR EARLY
NEONATAL DEATH IN PREMATURE
INFANTS BORN BETWEEN 28 TO 32
WEEKS' GESTATION

Objective: To analyze several obstetric risk 